\title{
EFFECT OF NITROGEN ON PHYSICAL AND OPTICAL PROPERTIES OF CARBON FILMS PREPARED BY MICROWAVE PLASMA CVD FOR PHOTOVOLTAIC SOLAR CELLS
}

\author{
Sunil Adhikary* \\ *Department of Meteorology, Tri-Chandra M. Campus, Kathmandu, Nepal.
}

\begin{abstract}
Nitrogen doped amorphous carbon thin films were deposited on silicon and quartz substrates by microwave surface-wave plasma chemical vapour deposition (MW SWP CVD) to investigate effect of nitrogen on properties of the carbon films. Deposition rate of the films found in the range of 5-7.5 nm/min. Optical band gap of the films decreased from 3.3 $\mathrm{eV}$ to $2.3 \mathrm{eV}$ corresponding to the increase of nitrogen flow rates from 0 to $10 \mathrm{sccm}$. RMS roughness of the undoped and Ndoped films was found to be $0.5 \mathrm{~nm}$ and $0.55 \mathrm{~nm}$ respectively suggesting that the amorphous carbon films deposited by MW SWP CVD are smooth.
\end{abstract}

Keywords: Carbon films; Nitrogen; Optoelectronic properties; Solar cells.

\section{INTRODUCTION}

Carbon, $\mathrm{C}$ is a remarkable element existing in different forms ranging from insulator diamond to metallic graphite to conducting / semi-conducting nanotubes (Krishna et al., 1997; Hayashi et al., 2001). Nitrogen incorporated amorphous carbon films are of great technological importance as many of their properties can be tailored by varying the amount of nitrogen incorporation for diverse industrial application (Badzian et al., 2001). Optoelectronic properties of amorphous carbon thin films strongly depend on deposition methods and deposition parameters. In terms of the carbonaceous precursor, the deposition methods can be classified into two categories. One is the physical deposition or sputtering method, while the other is chemical vapor deposition (CVD) (Umeno and Adhikary, 2005).

The sputtering methods, such as ion beam sputtering, magnetron sputtering and pulsed laser deposition usually use solid target. On the other hand, the CVD methods such as radio frequency (r.f.)/microwave (MW) plasma CVD and plasma-enhanced CVD involve the decomposition of hydrocarbon source gasses, such as methane $\left(\mathrm{CH}_{4}\right)$, Ethylene $\left(\mathrm{C}_{2} \mathrm{H}_{4}\right)$ and Acetylene $\left(\mathrm{C}_{2} \mathrm{H}_{2}\right)$. The gaseous phase of carbon source used in CVD has the advantage of better control of chemical composition and bonding structure in thin films over the solid source used in the physical deposition system (Rusop et al., 2003).
In order to improve amorphous carbon thin film deposition with the possibility of mass production, a novel method, namely MW surface-wave plasma (SWP) CVD has been developed (Umeno and Adhikary, 2005; Omer et al., 2005). Although properties of amorphous carbon thin films deposited by various methods have been reported in detail, properties of the MW SWP CVD deposited films for the application of photovoltaic solar cells have rarely been reported. In this paper, I report the effect of nitrogen doping on physical and optical properties of amorphous carbon thin films deposited by MW SWP CVD.

\section{MATERIALS AND METHOD}

Carbon thin films were deposited on silicon and quartz substrates by MW-SWP-CVD at low temperature $\left(<100^{\circ} \mathrm{C}\right)$. Figure 1 shows schematic diagram of the MW SWP-CVD system. The stage of this system is made by aluminum, and its diameter is about $200 \mathrm{~mm}$. The stage temperature can be controlled up to $200^{\circ} \mathrm{C}\left( \pm 5^{\circ} \mathrm{C}\right)$. The SWP was produced in a $300 \mathrm{~mm}$ diameter, cylindrical vacuum chamber by introducing a $2.45 \mathrm{GHz}$ microwave through a quartz window via slot antennae. The maximum microwave power of the system is $2500 \mathrm{~W}$. The vacuum system has two steps pumping, namely turbo molecular pump and dry pump. Deposition parameters such as MW power and gas flow ratio can be controlled in this system. A high plasma density with a uniform electron density of more than $10^{11} \mathrm{~cm}^{-3}$ is formed in the vacuum chamber

Author for Correspondence: Sunil Adhikary, Department of Meteorology, Tri-Chandra M. Campus, Kathmandu, Nepal. Email: sunirus2003@yahoo.com 


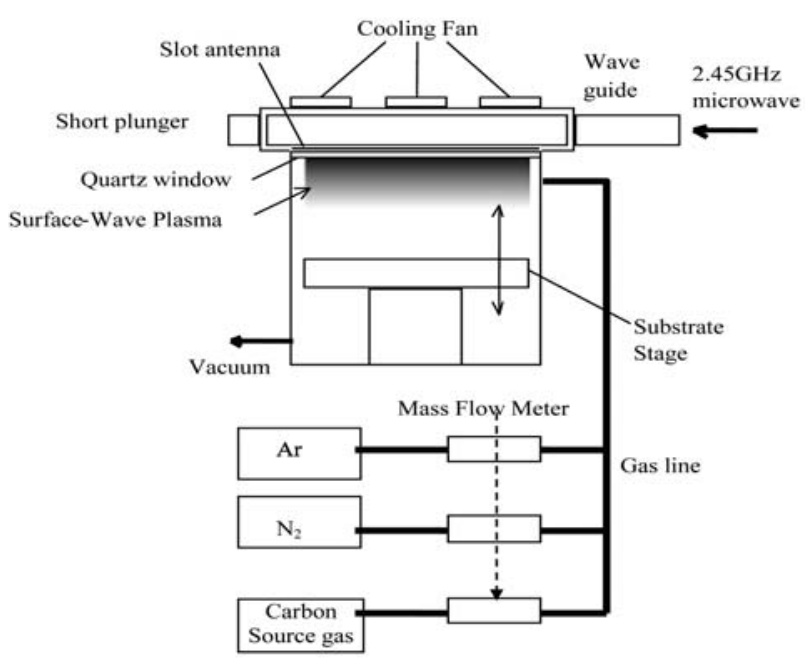

Fig. 1: Schematic diagram of the MW SWP CVD system.

and broadened in the down stream region due to particles' diffusion. For film deposition, Argon (Ar: $280 \mathrm{sccm}$ ) and ethylene $\left(\mathrm{C}_{2} \mathrm{H}_{4}: 10 \mathrm{sccm}\right)$ were used as carrier gas and carbon source gas respectively. Simultaneously nitrogen gas $\left(\mathrm{N}_{2}\right)$ (flow rates from 0 to $15 \mathrm{sccm}$ ) was injected into the chamber during film deposition. Before deposition, CVD chamber was evacuated at $5.0 \times 10^{-4} \mathrm{~Pa}$, and total gas pressure was held fixed at minimum (about $50 \mathrm{~Pa}$ ) during film deposition. The substrates (silicon and quartz) were cleaned beforehand by acetone and methanol in ultrasonic bath and only for $\mathrm{Si}$ substrates were etched with diluted hydrofluoric acid $\left(\mathrm{HF}: \mathrm{H}_{2} \mathrm{O}\right)(1: 10)$ in order to remove the native oxide layer from the surface. The launched MW power was typically $1000 \mathrm{~W}$.

The X-ray photoelectron spectroscopy (XPS) was measured by SSX-100 XPS system of Surface Science Instruments utilizing an AIKá (hí $=1486.6 \mathrm{eV}$ ) radiation as an X-ray source, under high vacuum conductions of about $10^{-10}$ Torr. UV/VIS/NIR spectroscopy (JASCO V-570), nanopics surface profiler (2100/NPX200) and atomic force microscope (AFM) were used to investigate optical and physical properties of the carbon films.

\section{RESULTS AND DISCUSSION}

\section{Film thickness and composition}

Thickness of the carbon films was measured by nanopics surface profiler. Deposition rate (film growth rate) was obtained as the quotient of the measured average thickness and time duration of the deposition. The increase of nitrogen incorporation did not show logical trend on deposition rate; film deposition rate was found in the range $5-7.5 \mathrm{~nm} / \mathrm{min}$. Figure 2 shows XPS spectra for a carbon film prepared with minimum nitrogen flow rate $(5 \mathrm{sccm})$; nitrogen peak found in the spectra indicate that $\mathrm{N}_{2}$ was successfully doped in the prepared carbon films.

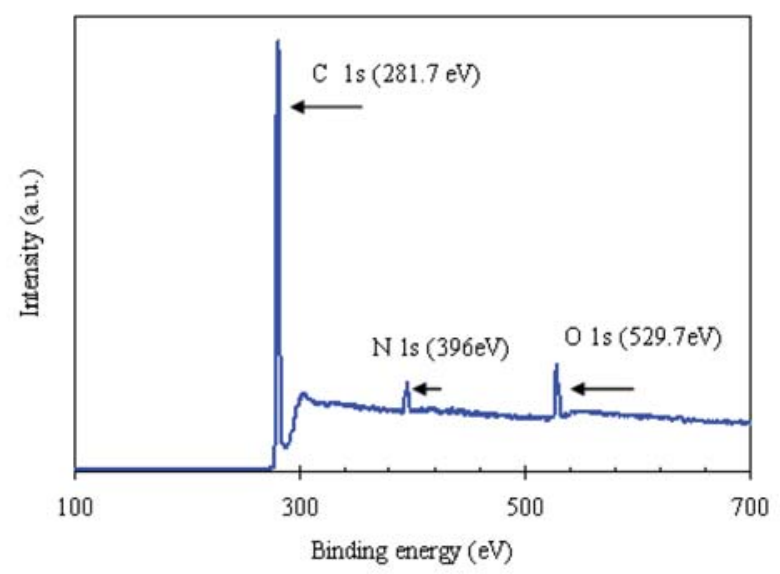

Fig. 2: Core level $\mathrm{X}$-ray photoelectron spectra of carbon (C 1s), nitrogen ( $N$ 1s) and oxygen ( $O$ 1s) for a nitrogen incorporated $\left(\mathrm{N}_{2}=5 \mathrm{sccm}\right)$ carbon film.

\section{Surface morphology}

Surface morphology of the carbon films was studied by AFM measurements. Figures 3A and 3B show AFM images of undoped and $\mathrm{N}_{2}$ doped $\left(\mathrm{N}_{2}=5 \mathrm{sccm}\right)$ films respectively. The root mean square roughness (RMS) of the undoped and $\mathrm{N}_{2}$ doped films were found to be $0.5 \mathrm{~nm}$ and $0.55 \mathrm{~nm}$ respectively. It is evident that the RMS roughness increased with the incorporation of $\mathrm{N}_{2}$, however, the increase is negligible. This extreme smoothness suggests that the amorphous carbon films deposited by MW SWP CVD are smooth compared with the films prepared by other deposition methods (Kim et al., 1996; Hartmann et al., 1998).

\section{Optical properties}

Reflectance and transmittance measurements by UV/VIS/ NIR spectroscopy in the range of 200-2000 nm were carried out to study the optical characteristics of the films. The absorption coefficient (á) was calculated by the reflectance and transmittance, and the film thickness data. The optical band gaps were obtained by Tauc plot (Tauc et al., 1966; Umeno and Adhikary, 2005). The Tauc optical band gap ( $\left.\mathrm{E}_{\mathrm{g}}\right)$ was obtained from the extrapolation of the linear part of the curve at a $=0$ by using the Tauc equation,

$$
(\alpha h v)^{\frac{1}{2}}=B\left(E_{g}-h v\right)
$$

where $B$ is the density of the localized state constant.

Figure 4 shows the variation of $\mathrm{E}_{\mathrm{g}}$ for the films obtained at different $\mathrm{N}_{2}$ flow rates into the CVD chamber. The $\mathrm{E}_{\mathrm{g}}$ decreased nearly exponentially from $3.3 \mathrm{eV}$ to $2.3 \mathrm{eV}$ corresponding to the increase of $\mathrm{N}_{2}$ flow rates from 0 to 10 sccm. Nagatsu et al. (2000) also reported similar result, and the trend of decreasing $\mathrm{E}_{\mathrm{g}}$ with increasing $\mathrm{N}_{2}$ was interpreted as an increase in disorder in the films. With further increasing the $\mathrm{N}_{2}$ flow rate $\left(\mathrm{N}_{2}\right.$ flow rate $\left.>10 \mathrm{sccm}\right), \mathrm{E}_{\mathrm{g}}$ did not decrease and the curve nearly stabilizes. For photovoltaic application of carbon film, control of $E_{g}$ is indispensable, which is desirable to be nearly $1.5 \mathrm{eV}$. The $\mathrm{E}_{\mathrm{g}}$ of the as deposited films 

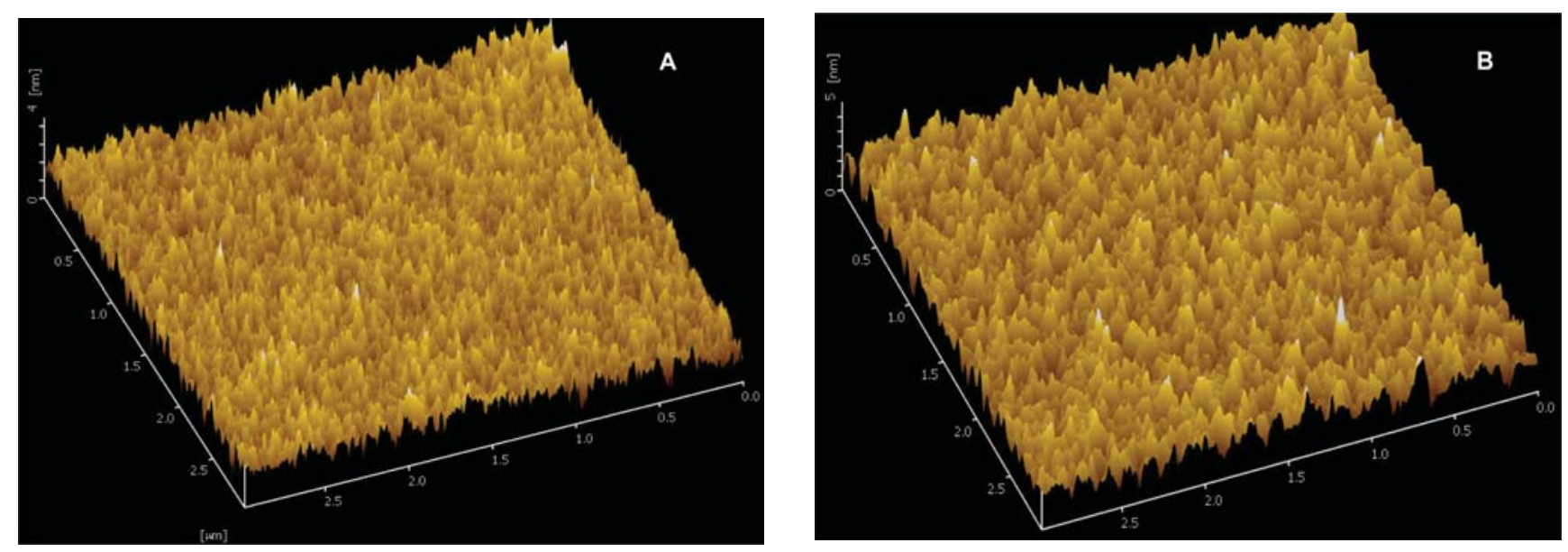

Fig. 3: AFM images of three-dimensional surface morphology for samples deposited in different $\mathrm{N}_{2}$ flow rates. (A) undoped or $\mathrm{N}_{2}$ free, (B) doped $\left(\mathrm{N}_{2}=5 \mathrm{sccm}\right)$.

are still quite high for the application of photovoltaic solar cells.

\section{CONCLUSIONS}

The effects of nitrogen doping on physical and optical properties of carbon films deposited by MW SWP CVD were investigated. Deposition rate of the films was found in the range $5-7.5 \mathrm{~nm} / \mathrm{min}$. The XPS measurement showed that the intensity of $\mathrm{N}$ peak is in the low energy region $(396 \mathrm{eV})$, indicating that $\mathrm{N}$ was effectively doped into the amorphous carbon films during films deposition. The $\mathrm{N}$ doping into the films during deposition resulted the decrease of optical band gap of the films from $3.3 \mathrm{eV}$ to $2.3 \mathrm{eV}$. The RMS roughness of the undoped and $\mathrm{N}$-doped films were found to be $0.5 \mathrm{~nm}$ and $0.55 \mathrm{~nm}$ respectively suggesting that the amorphous carbon films deposited by MW SWP CVD are smooth. The experimental results show that nitrogen incorporation into the amorphous carbon films plays a major role in controlling the physical and optical characteristics of the films. Successful control of nitrogen incorporation into amorphous

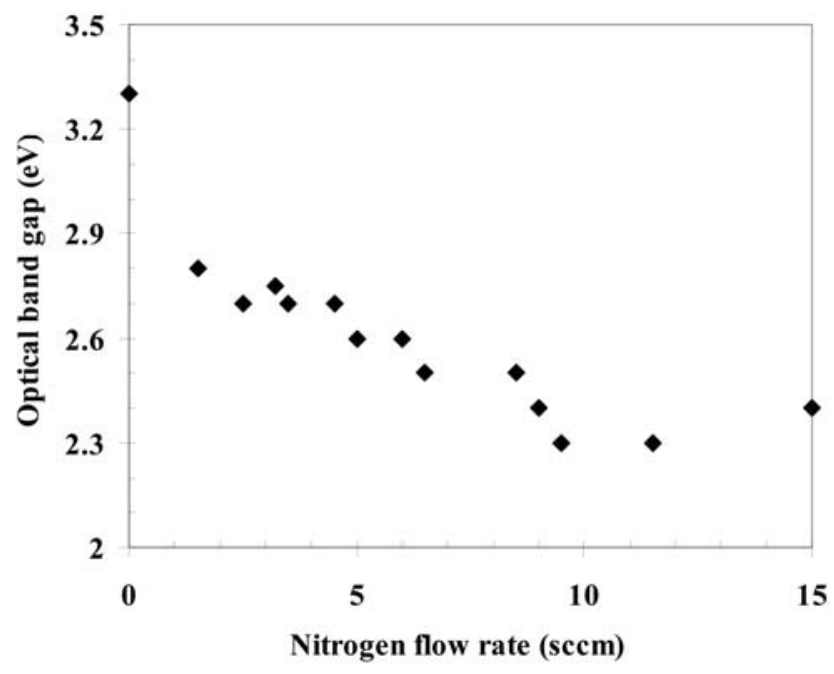

Fig. 4: Optical band gap of the carbon films prepared with different $\mathrm{N}_{2}$ flow rates. carbon films coupled with proper optimization of film properties, such as electronic and electrical help to realize low cost and environmentally friendly carbon-based photovoltaic solar cells in the future.

\section{ACKNOWLEDGEMENT}

This work was supported by New Energy and Industrial Technology Development Organization (NEDO) under the Ministry of Economy, Trade and Industry (METI), Government of Japan. The author thanks Dr. Sudip Adhikari, Post-Doc Researcher at the Department of Electronics and Information Engineering, Chubu University, Japan for characterization of the carbon films.

\section{REFERENCES}

Badzian, A., Badzian, T., Breval, E. and Piotrowski, A. 2001. Thin Solid Films (398):170.

Hayashi,Y., Yu, G., Rahman, M.M., Krishna, K.M., Soga, T., Jimbo, T. and Umeno, M. 2001. Journal of Applied. Physics (89): 79247931.

Hartmann, J., Schreck, M., Baur, T., Huber, H., Assmann, W., Schuler, H., Stritzker, B. and Rauschenbach, B. 1998. Diamond Related Materials (7): 899.

Kim, J.H., Kim, Y.H., Choi, D.J. and Baik, H.K. 1996. Thin Solid Films (289): 79.

Krishna, K.M., Soga, T., Mukhopadhyay, K., Sharon, M. and Umeno, M., 1997. "Photovoltaic solar cell from camphoric carbon A natural source", Solar Energy Materials \& Solar Cells (48): 25-33.

Nagatsu, M., Sano, T., Takada, N., Guang, W.X., Hirao, T. and Sugai, H. 2000. Japanese Journal of Applied Physics (39): L929.

Omer, A.M.M., Adhikari, S., Adhikary, S., Uchida, H. and Umeno, M. 2005. Applied Physics Letters (87): 161912.

Rusop, M., Mominuzzaman, S.M., Soga, T., Jimbo, T. and Umeno, M. 2003. Japanese Journal of Applied Physics (42): 2339.

Tauc, J., Grigorovici, R. and Vancu, A. 1966. Physics Status Solid (15): 627.

Umeno, M. and , Adhikary, S. 2005. Diamond and Related Materials (14): 1973-1979. 